AIAA - 2000-3791

\title{
DESIGN AND TESTING OF DEMONSTRATION UNIT FOR MAINTAINING ZERO CRYOGENIC PROPELLANT BOILOFF
}

\author{
csi.c: haialaiaal
}

\author{
W.G. Dean, Chief Engineer \\ Dean Applied Technology Co., Inc. \\ Huntsville, AL 35816 USA
}

\begin{abstract}
$\underline{\text { Abstract }}$
Launching of cryogenic propellants into earth orbit and beyond is very expensive. Each additional pound of payload delivered to low earth orbit requires approximately 35 pounds of additional weight at liftoff. There is therefore a crilical need 10 minimize boiloff in spacecraft long term missions/systenis. Various methods have been used to date, Including superinsulation and thenmodynanuc vents to reduce boiloff. A systen was designed and tested as described horein that will totally eliminate boiloff. This system is based on a closed-loop. two-slage pulse lube refrigerator with a net refrigeration of four watts at $15 \mathrm{~K}$ for the recovery of hydrogen propellant. It is designed to operatc at $30 \mathrm{~Hz}$ which is an order of magnitude highicr than olher typical pulse tube refrigerators. This high frequency allows the use of a much sinaller, lighter weight compressor. Tlus paper describes the system design, fabrication and test results.
\end{abstract}

\section{Background And Introduction}

The need for a means of propellant boiloff recovery has been recognized almost since the begimning of the U.S. space program. In fact, Dr. Werner Von Braun, farnous rocket scientist and former Dircctor of NASAMSFC was personally interested in and funded work in this area. These efforts were of particular interest to him with respect to a Mars mission. Some of those early efforts are documented in Reference 1. Since that time, significance improvenents have been made in spacecraft cryogenic refrigeration technology which we have incorporated into our current efforts. Spacecraft Cryogenic propellant tanks are normally vented periodically to prevent excessive pressure buildup. This pressure buildup is caused by the boiling off of propellant due to heat leaks through the tank walls, insulation and vilious struclural penctrations. In the real world, this heat leak can never be entirely eliminated no matter how good the insulation and design. This venting obviously wastes vitally needed propellants. Each pound of propellant delivercd to low earth orbit requires about 35 pounds of weight at launch. For other higher orbits and interplanetary missions the launched-weight-to-payload ratio is of course even higher. Therc is therefore a critical necd for a mcans to recover this propellant boiloff and return it to its tank. The efforts described in this paper are aimed at meeting this need.

This work was performed under a NASAMSFC Small Business Teclinology Transfer Contract. Dean Applied Technology Co.. Inc. (DATCO) was the Snall Business Concern with the University Or Alabama (UAH) in Huntsville as the partnering Research Institution. 


\section{Sunmary Of Work Acoomplished}

This cffort was accomplished in two phases. Phase 1 investigated a range of possible methods for bolloff recovery, selected the best approach and determined the feasibility of this approach. The pulse tube refrigerator was selected as the best solution. In Plase 2, this system was designed, fabricated and tested.

During Phase 1, the following methods were considered for boiloff recovery:

- A tolal of tweive Actwe Refrigeration cycles

- A direct - condensing space radiator

- Use para-to-ortho hydrogen heat of conversion as a low temperature heat sink in a condensing heat exchanger

- Hydrogen boiloff combustion as a poiver source to drlve an active refrigerotion system, thus eliminating the need for. spocecraft electrical power.

During Phase 1, it was conclusively shown that it is feasible to use Pulse Tube Refrigcration Teclinology to reliquefy cryogenic propellant boiloff and that this teclunology has the following advantages:

- Uses a simple tube known as a "pulse tube", an orifice and a reservolr rather than a moving expander at the cold end to produce nefrigeration

- No vibration produced at cold end

- Can be flight qualified on the ground, theneby eliminating expensive jight testing

- Dymamics are significantly simpler than other cycles

- Fever moving parts - hence

- Longer life

- Higher reliability

- Lover cost

- Uses no CFC or HCFC. refrigerants

- Requires no phase change in zero-g, hence no bolling or condensing heat iransfer or phase separators

- There is currently significunt interest and efforts to commercialize this technology in Japan. China and USA.

As a result of Phase 1 cfforts, it was concluded and recommended that a pulse tube refrigerator should be built and tested. 


\section{Requirementa/Groundnules}

The first step of Phaso I was to establish groundrules and requirements. Our boilorr rates were bused on the results of Reference 1 design which used the following:

- Tank diameter: $3.9 m$

- Tonk length: $9.1 \mathrm{~m}$

- Insulation: 4 MIII blankets cach $2.54 \mathrm{~cm}$ thick

This resulted in a hydrogen boiloff rate of $.028 \mathrm{Kg} / \mathrm{hr}(.062 \mathrm{lbm} / \mathrm{hr})$ at a pressure of $101 \mathrm{~K}-\mathrm{N} / \mathrm{m}^{2}$ (14.7 Psia). This resulted in a heat load of approximately four Watts. We selected a temperaturc of $15 \mathrm{~K}$ at which this four Watts of refrigeration must be produced. This gives us a teimperature drop of $5 \mathrm{~K}$ across the condensing heat exchanger for liquefying hydrogen at $20 \mathrm{~K}$ at the given prossure.

\section{Active Refrigeration Cycles Considered}

A trade study was perlormed which included seven recuperative refrigeration cycles and five regenerative refrigeration cycles. An investigation was performed on each of these 12 cycles which provided information on history/background, how it works, current applications, advantages and disadvantages and methods for application to our propellant boiloff problem. This trade study employed the Kepner-Tregoe Analysis (KTA) Trade Methodology which provides an explicit, quantitative comparison of the candidate, alternative systems and results in numerical scoring of each alternative. This method accounts for varying importance of evaluation criteria by assigning weigliting faclors $10 \mathrm{cach}$ criteria. Eacli cycles was scored with respect to 15 criteria. The results yielded a score of 9330 points for the pulse lube compared to 7130 for its nearest competitor and 1845 for the cycle with the lowest score. Thercfore the pulse tube was selected as the system to be employed for this application. Using our best cnginecring judgment based on experience in dealing with numerous space prograns, Uhe following weighting factors as shown in Table I were assigned to each of the 15 cvaluation criteria.

\begin{tabular}{|c|c|}
\hline Criterial & Weighting Factor \\
\hline Weight & 10 \\
\hline Volume & 4 \\
\hline Power & 10 \\
\hline Cost & 10 \\
\hline Life & 9 \\
\hline Vibration & 3 \\
\hline Complexity & 9 \\
\hline Cold-End Moving Parts & 6 \\
\hline Compression Ratio & 6 \\
\hline Staging Capability & 6 \\
\hline Single Compressor to Drive Multiple Stages & 6 \\
\hline Experience Base & 4 \\
\hline On-going Supporting Research/Development by Others & 2 \\
\hline Technology Readiness Level & 3 \\
\hline Flight Qualification on Ground & 7 \\
\hline
\end{tabular}

Table 1: Weighting Factors Assigned To Each Evaluation Criteria

Amcrican lnstitute Of Aeronautics And Astronauts 
The following 12 refrigeration cycles were considered:

- Precooled Linde-Hampson

- Clavie

- Helinm-Refrigerated

- Cascade

- Kapilza

- Heylandt

- Dual-Pressure Cloude

- Stirling

- Pulse Trube

- Vuilleumier

- Gifford-Macdahon

- Duplex Stirling

\section{Space Radiator Considerations}

Any time that thermal energy has to be rejected from a spacecraft, the first and most obvious method that comes to mind is to use a radiator. Decp space provides a virtually infinite heat sink if it can be made compatible with other spacecraft requirements. Various thermal radiators have been used successfully on spacecraf for years. We therefore investigated the feasibility of using a radiator to perform the heat rejection necessary to meet the stated requircments of this boiloff recovery system.

A thermal analysis model was set up consisting of 1,000 nodes radiating to an input sink temperature. A mass flow rate of hydrogen flowing turough the radiator of $.06257 \mathrm{lb}$ hr was used in all cases per the established requirements. Specific heat, view factor to space, emissivity, and initial temperature were input as variables. A varying incremented area of each node was input. These inputs were then used to calculate outet temperature, total surface area and total heat rejected. The temperature step betwecn nodes was not allowed to exceed approximately 1.8 degrecs $\mathrm{K}$. Ittcrations were perforned until the area needed to mect the needed outlet temperature and/or heat rejection were attained. 
A total of six scenarios or cascs were analyzed as described in Table 2 :

\begin{tabular}{|c|l|}
\hline Case No. & Case Description \\
\hline IA & Boiloff circulated directly through radiator \\
\hline IB & $\begin{array}{l}\text { Circulate boiloff through vapor shields beforc } \\
\text { entering radiator, remove superlieat added by vapor } \\
\text { shiclds }\end{array}$ \\
\hline 2A & $\begin{array}{l}\text { Compressor used to raisc temperature of boiloff } \\
\text { before entering radiator - no vapor shields }\end{array}$ \\
\hline 2B & $\begin{array}{l}\text { Use J-T valve to return pressure to 14.7 Psia after } \\
\text { existing the radiator - vapor shields used }\end{array}$ \\
\hline 3A & $\begin{array}{l}\text { Use recuperative heat exchangers before } \\
\text { compressor and before JT valve - no vapor shields }\end{array}$ \\
\hline 3B & \begin{tabular}{l} 
Same as 3A but with vapor slields \\
\hline
\end{tabular}
\end{tabular}

Table 2: Description Of Cases Analyzed In Space Radiator Considerations

The conclusion of these efforts was that this system was not found to be feasible because of the high pressure, large radiator areas, and low effective sink temperature required.

Investigation Of The Use Of Para-Ortho Conversion Of Liquid Hydrogen As A Heat Sirtk

Hydrogen can exist in cither of two states. Parahydrogen (p- $\left.\mathrm{H}_{2}\right)$ and Orthohydrogen $\left(\mathrm{O}-\mathrm{H}_{2}\right)$. The difference in these two fornis is in the relative orientation of the nuclear spins of the two atoms composing the diatomic molecule. In the ortho form, the nuclear spins of the two atoms in the molecule are parallel, that is in the same direction. In the para form. the spins are antiparallel. There is a significant difference in energy levels of these two states. The heat of conversion can be up to $702 \mathrm{~J} / \mathrm{gm}$ (302 BTU/bm). This is significant when comparcd to the heat of vaporization which is $446 \mathrm{~J} / \mathrm{gm}$ (192 BTU/hbm). The equilibrium ratio of para-to-ortho form depends upon lemperature. "Nomnal" hydrogen $\left(\mathrm{n}-\mathrm{H}_{2}\right)$ refers to liydrogen at ambient and higher temperatures, and consists of $75 \%$ ortho and $25 \%$ para. At the boiling point of $20 \mathrm{~K}$ and onc-almosphere pressure, the equilibrium composition is essentially $100 \%$ para. The equilibrium mixture of hydrogen at any ternperahure is known as "equilibrium" hydrogen $\left(\mathrm{c}-\mathrm{H}_{2}\right)$. If liquid liydrogen is producad in the ortho state, it will gradually and spontaneously convert to its equilibriun state of $100 \%$ para with the corresponding release of the heat of conversion. Since the heat of conversion is greater than lic heat of vaporization, the liquid hydrogen will vaporize a major portion of itself even without the addition of any heat from outside sources such as conduction through the tank walls and insulation. Thus, liquid ortholiydrogen is unstable and will result in loss of about $70 \%$ of its inass due to spontaneous conversion over a period of time. Therefore for storage rcasons, liquid bydrogen is produced conunercially in the $100 \%$ para form. The conversion from ortho to para is cirried out as an integral part of the liquefaction process using heat exchangers and catalytic converters. Two basic types of catalysts have been developed, namely iron-oxide and nickel-silicate calalysts. The iron oxides are chenper but less effective, i.e. less active than the ulickel-silicates. During this contract we investigated the possibility of using this conversion process energy change as a heat sink for the reliquefier system. The ortho to para conversion is exothermic, releasing heat, while the para to ortho conversion is endothermic, requiring lieat to be added thus having the potential of serving as a heat sink in one side of a heat exchanger. This concept was previously mentioned in Reference 1 , but was not thoroughly investigated. Operation of this concept is as follows (quoted from Reference 1): "-..- parahydrogen from the storage tank is heated in a counler-flow heat exclianger to approximately 125R. At this temperature, it is passed through a catalyst to promote the conversion of a portion of the paralyydrogen to orthohydrogen. The energy absorbed in the conversion 
process is einployed as the heat sink for a reliquefier. The partialty converted hydrogen strean is then cooled in the opposite side of the counter-flow heat exchanger and returned to the storage tank. The net effect of this system is that the heat transfer through the tank insulation and the energy supplied to the reliquefier compressor are stored in the hydrogen. The ortholiydrogen so produced will, of course, spontaneously but slowly convert back to parahydrogen and liberate the stored energy. However, for up to the order of 1000 hours, the fornard conversion mite can be made to exceed the back conversion rate and no-boiloff-loss conditions can be maintained."

Our concept differs from that of Reference 1, in that we want to use hydrogen in the liquid state whercas Reference 1 proposed to use vapor phase. In Reference 1, the lemperature of the vapor would be raised to $70 \mathrm{~K}$ where the cquilibrium composition was other than $100 \%$ para. The addition of heat in the presence of a catalyst would force the mixture to the equitibrium composition with the accompanying absorption of heat fron the portion of the strcam to be cooled. The converted portion would be vented carrying with it the absorbed hcat. Thus a system could be designed and operated that could at best only recover some fraction of the boiloff.

Our system as conceived would provide a heat sink at the liquid hydrogen temperature of $20 \mathrm{~K}$ and a lieat of conversion of $702 \mathrm{~J} / \mathrm{g}$ (302 BTU/lb) which would be a real "gold mine" brcakthrough in dealing with the boiloff recovery problem. This converted liquid could be stored separetely until used in the next engine burn.

However, in order for this concept to work, the liquid nust be converted out of its equilibrium state "backward" to some non-equilibrium condition. When dealing with the initial liquid hydrogen storage problem years ago, the devclopers were tworking with getting the mixture to progress "forward" toward equilibrium which thcy were able to speed up by the use of catalysts. When they found a solution to their slorage problem, there was no further commercial interest in the "backward" conversion problem.

We thoroughly scarched the litcrature for clucs on how to do a para to ortho conversion. A smal] portion of the early work dealt with conversion in the liquid state. However, the practical solution was to do the conversion at higher temperatures in the vapor state. Therefore there is litlle information or experience available in the literature for conversion in the liquid state. We were unsuccessful in finding a way of producing this process. Therefore we were unsuccessful in utilizing llis concept for our recovery problem.

\section{Preliminary Dcsign}

As a result of these Phase 1 efforts, the pulse tube concept was selected as the best molhod for this application. A preliminary design was developed as shown on Figure 1. This is a three-stage concept which lifts four Watts of cooling from $15 \mathrm{~K}$ to $290 \mathrm{~K}$. Heat is assumed to be rejcctcd to the central spacecraft thermal control system such as a coolant fludd loop. This design is based on the orifice pulse tube concept whose operation is described below. Each of the three stages consists of a pulse tube, hent exchangers, and regenerator with orifice and reservoir which provide the phasc lag between pressure and mass now in the pulse tube which is required 10 produce cooling. This design also utilizes the double inlet concept to further entance the phase lag and provide additional cooling capacity. The first stage lifts heat from $195 \mathrm{~K}$ to $290 \mathrm{~K}$, the second stage from $51 \mathrm{~K}$ to $195 \mathrm{~K}$ and the third stage from $15 \mathrm{~K}$ to $51 \mathrm{~K}$. Gascous hydrogen propellant boiloff is passed through the cold-end heat exchanger at $15 \mathrm{~K}$ where it is condensed into liquid.

csi.c: laiaalaiaa2 


\section{Pulsc Tube Refrigeration History And Background}

The Pulsc Tube Refrigeration Cycle is a relative newcomer compared to other refrigcration cycles. In 1963. Professor Giflord of Syracuse University and lis graduate student, R. Longsworth, noticed that blanked off plumbing lines connected to gas compressors became hot at the closed end. By connccting the plumbing line to a compressor through a regenerator, cooling was achieved at one end and heating at the other, Uhus the birth of the Basic Pulse Tube Refrigerator. The original one-stage cooler was reported to have achicved $150 \mathrm{~K}$ while a two-stage device achieved $120 \mathrm{~K}$. After a few years, the coolers had reached $120 \mathrm{~K}$ and $85 \mathrm{~K}$, respectively. Although the cooler raised much curiosity, its efficiency was disappointing and by the end of the 1960's, its use as a practical cooler was not being pursued. In the late 1970's. Dr. J. Wheatley of the Department of Energy's Los Alamos National Laboratory became interested in a related technology - thermoacoustic engincs and coolers. These devices are driven to operate at acoustic resonance with a loudspeaker and have no moving parts other than the working fluid and the loudspeaker. Howcver, its efliciency was lower than the Basic Puise Tube and it did not see practical applications.

In 1981, Dr. Pete Kittle of NASA Ames Research Center, who is the source of much of this infornation on the history of Pulse Tube Refrigeration, heard a talk by Dr. Wheatley and recognized that a cooler with a single moving part had much potential for space applications. The single moving piston in the Pulse Tube gave it the ability to be more reliable, simpler to control, and cheaper than the Stirling Cycle Cooler. In addition, since the Pulse Tube has no moving parts at the cold end, it offers longer lifetime in cryogenic applications and eliminates vibration at the cold end which is great for detector applications.

Shortly thereafler, Dr. Kittle joined with Dr. Ray Radebaugh of the National Institute of Slandards and Teclinology (NIST) and began developing Pulse Tubes as cryocoolers. In 1983, they made a breaktlirough when, without adding any moving components, they were able to improve the efficiency of the Pulse Tube Refrigerator by increasing the plase shift between the pressure and the mass flow. This was done by connecting an orifice and a reservoir to the hot end of the Pulse Tube. This improvement became the standard Pulse Tube Refrigerator configuration and became known as the Orifice Pulse Tube. Single-stage Orifice Pulse Tube (OPT) Refrigerators, have reached $30 \mathrm{~K}$ while a three-stage OPT has reached $3.6 \mathrm{~K}$.

By the late 1980's. Pulse Tube development had begun at many laboratories around the world including the United States, China, Japan, France, and Germany. A group led by Professor Matsubara of the Nihon University in Japan, developed a moving plug or hot piston Pulse Tube. In this configuration. efficiency was increased by adding a second moving component, but it was not at the cold end.

According to Dr. Kittel, the most important development has been the innovation of the double inlet Pulse Tube by Dr. Zhu, et al. of Xl'an Jiaotong University in China and the subsequent refinement into the multiple bypass Pulse Tube by Dr. Zhou of the Academia Sincia in China. This innovation offered additional efficiency improvements.

\section{How The Orifice Pulse Tube Refrigerator Operates}

The operation of the Orifice Pulse Tube is as follows. First, the gas is compressed in the compressor. It then tlows through the compressor aftercooler, where heat is rejecled to the surroundings or a cooling water loop. Next, the gas flows through the regenerator which is basically an "economizcr", or "ibermal spongc", conserving cooling from one cycle to the next. The gas then enters the cold-end heat exclianger where heat is added to the gas from the surroundings, thus producing refrigeration. Next, lie flow enters the pulse tube, orifice and reservoir. The purpose of these three components is to produce at phase shiff between the mass flow and pressure. Without this phase shift, there would be no cooling. In the pulse tube the gas shuttles back and forth between the hot and cold ends rather than circulating continuously around a loop, as in some refrigeration cycles. Heat is lifted against the temperature gradient and rejected at the hot-end heat exchanger, to the surroundings or to a cooling water loop. For a more detailed description of how the pulse tube operates, see Reference 2.

American Institute Of Aeronautics And Astronauts 


\title{
Pulse Tulx Cryoconler Detail Design
}

\author{
csi.c:Laiaalaiaa3
}

More detailcd analyses during Phase 2 showed that we could simply the Phase 1 preliminary design. It was shown that a two-stage design could be used rather than our original three-stage configuration. Therefore we did a detailed design and fabrication of a two-stage pulse tube configuration. These detailed analyses were done by Dr. Ray Radebaugh of the National Institute Of Standards and Teclunology (NIST). Dr. Radebaugh is one of the world's foremost experts on pulse tube refrigeration, laving written numerous papers on the subject and designed numerous units. We were fortunate to have latd his inputs to our project.

Figure 2 shows this upgraded design. 'This two-stage cryocooler is designed to provide four Watts of net cooling at $15 \mathrm{~K}$, which is $5 \mathrm{~K}$ degrees below the $20 \mathrm{~K}$ liquefaction temperature of hydrogen at 101 $\mathrm{KPa}$ (14.7 Psia) pressure. Both first and second stages employ tapered tube configurations for improved efficicncy. Both tubes are made of $254 \mathrm{~mm}\left(.010^{\prime \prime}\right)$ thick, 304 stainless steel with butt welded seams. The first stage tube is $8 \mathrm{~cm}$ (3.15") long, the second stage tube is $10 \mathrm{~cm}\left(3.9^{\prime \prime}\right)$ long. The first and second stage regenerators are also madc of $.234 \mathrm{~mm}\left(.010^{\prime \prime}\right)$ thick 304-stainless steel with a butt-welded seam. Thic first and scoond stage regenerator matrix malerials are 400-mesh stainless steel screens and .127mm. (005") diameter lead spheres respectively. This system is also designed with double inlet valves in both first and sccond stages. The first-stage primary and secondary orifice valves have flow coefficients of 0.17 and 0.19 respectively and the second stage primary and secondary valves have flow coefficients of 0.098 and 0.120 respectively. Our system is also designed with inertance tubes in both first and second stages for improved cooling capability. The peak mass flow rates for the first stage cold end and warm end heat exchangers are 7.48 and $1.95 \mathrm{grams} / \mathrm{sccond}$, respectively, and 10.7 and $0.95 \mathrm{grams} / \mathrm{second}$ for the second stage cold-end and warm-end heat exchangers respectively. The first-stage regenerator intet peak mass flow ratc is $\mathbf{1 9 . 6}$ grams/second.

The first stage cold end heat exchanger is designed to operate at $70 \mathrm{~K}$ when the second stage coldend heat exchanger is at $15 \mathrm{~K}$ and pumping a 4 -Watt load. Heat to be removed by the 1st stage warm-end licat exchanger is 45.2 Watts and 16.6 Watts for the second-stage uarm-end heat exchanger.

All heat exclanger bodies are made of copper with copper screens brazed inside. The first stage warml-cud and cold-end heat exchangers and the second stage wanm-end heat exchangers use 100 mesh screens with a wire diameter of $.114 \mathrm{~mm}\left(.0045^{\prime \prime}\right)$. The second stage cold-end heat exchanger uses 150 mesh screens with $.066 \mathrm{~mm}$ (.026") diameter. As seen in Figure 3, tuis is a linear design with the warmends on eacli end and the cold heat exchangers in the middle.

Our unit uses helium gas as the working fluid in order to get to this $15 \mathrm{~K}$ minimum temperature. The mcan operating pressure is about $1.46 \mathrm{MPa}(212 \mathrm{Psi})$ with a peak-to- peak pressure variation of about $654 \mathrm{KPa}(95 \mathrm{Psi})$ at the first stage regenerator inlet.

The unit operates at $30 \mathrm{~Hz}$ which is almost an order of magnitude faster than most pulse tube crocoolers previously reported in the literature which typically operate at 1 to $3 \mathrm{~Hz}$. This high frequency opcration presents challenges in the regenerator design. However this high frequency was chosen 10 allow the use of a smaller, lighter-iveight lincar compressor in a future flight weight designs. A low-ircquency linear compressor to drive this unit would be huge. Our concept is to use a small compressor but rull at high speed to deliver the required mass flow rates and pressures. This can be comparcd to a race car engine which is run at very high RPM to get a lot of power out of a small engine.

All our warm-end heat exchangers are water-cooled. All these components are brazed together as seen in Figure 2 and mounted inside a small vacuum tank for testing. This task was fabricated by UAH. All four orifice valves are exiernal to the test chamber to allow for orifice flow coefficient adjustment and tuning during testing. 
Figure 3 shows these components mourted on one of the test vacuum chamber bulkheads and boing insulated with multilayer insulation (MLI) Blankets. The test cliamber is evacuated with a turbomolecular and a mechanical vacuum pump during testing. This mininizes parasitic heat leaks to the cold componenis.

Instrumentation for this unit consists of thermocouples and a silicon diode for temperature measurements and dynamic and static pressure measurements. Data is recorded, reduced and presented using Labview software and National Instruments P.C.-based data acquisition boards.

Our cryocooler unit is driven by two commercially available alr conditioning compressors operated in parallel. Comunercially available oil separators, filters and aftercooler arc also used.

The pulsc tube concept requires an oscillating flow of working fluid, hence the name "pulse". In order to convert the circulating flow from a typical compressor to oscillating flow, we have designed and built a rotary valve. This valve allows flow of helium into and then back out of the cooling components. Valve ports connecting the first stage inlet to the main compressor feed lines are sequentially opened and closed. It is first connected to the high pressure line which causes flow to enter the inlet. Then the high pressure port is closed and the low pressure port is opened causing the flow to be evacuated. Plenum chambers are used on both the high pressure and low pressure sides of the rotary valve.

Figure 4 shows the completely assentbled components mounted inside its test rack.

\section{Test Results}

This unit has been completely assembled, checkcd out and leak checked. It is now nunning and cooling and is being generated. There have been some problems in getting the required $654 \mathrm{KPa}$ (95 Psi) peak-to-peak pressure on the pulses to the first stage heat exchanger due to leaks in the rotary valve and other operating problems. We have also had some problems with getting totally oil-free helium to our cold-cnd components. In spite of these problems, we have at the time of this writing, attained a temperature of $170 \mathrm{~K}$ $(-150 F)$.

Figurc 5 shows typical measured pressure pulses to the first stage regenerator inlet. Figure 6 shows a typical pressure pulse waveform. Figure 7 shows a typical temperature versus time lustory for the second slage cold-end heat exclianger witl no applied refrigeration load. A resistance heater is to be installed on the second stage heat exchanger to simulate refrigeration load in futurc tests.

At the time of this writing testing is being continued. Testing consists of a trial and error process in which the four orifice flow coefficlents and other operating parameters are systematically varied and thic resulting effect on temperature is observed until the minimum value is reached.

\section{Future Work}

We plan to continue this testing until our desired temperature and refrigeration load are reached. We also plan to upgrade this linear design to a folded configuration which will place all penetrations on a single bulkliead rather than two bulkheads. This will simplify our interfacing with a test chamber, dewar, propellant tank and/or propellant lines on a vehicle.

We also plan to pursue the development of an eflicient, thight weight linear compressor to replace our commercial compressor and rotary valve. The linear compressor concept produces oscillating flow, or pulses, directly to the cooling end components without the need for the rotary valve.

American Instilute Of Aeronautics And Astronauts 


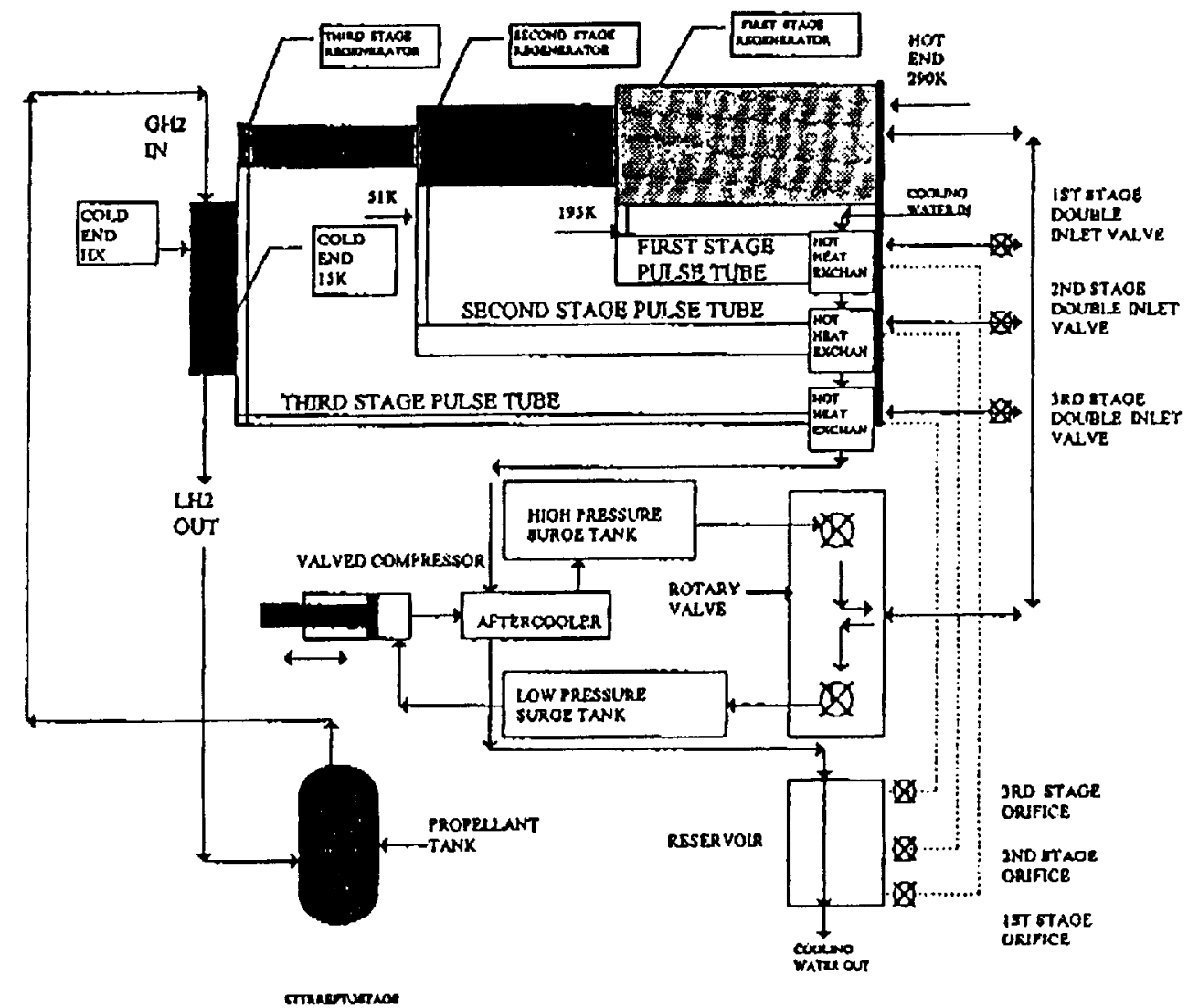

FIGURE 1: SCHEMATIC FOR THREE-STAGE PULSE TUBE BOILOFF RECOVERY SYSTEM PRELIMINARY DESIGN CONFIGURATION DEVELOPED DURING PHASE 1 


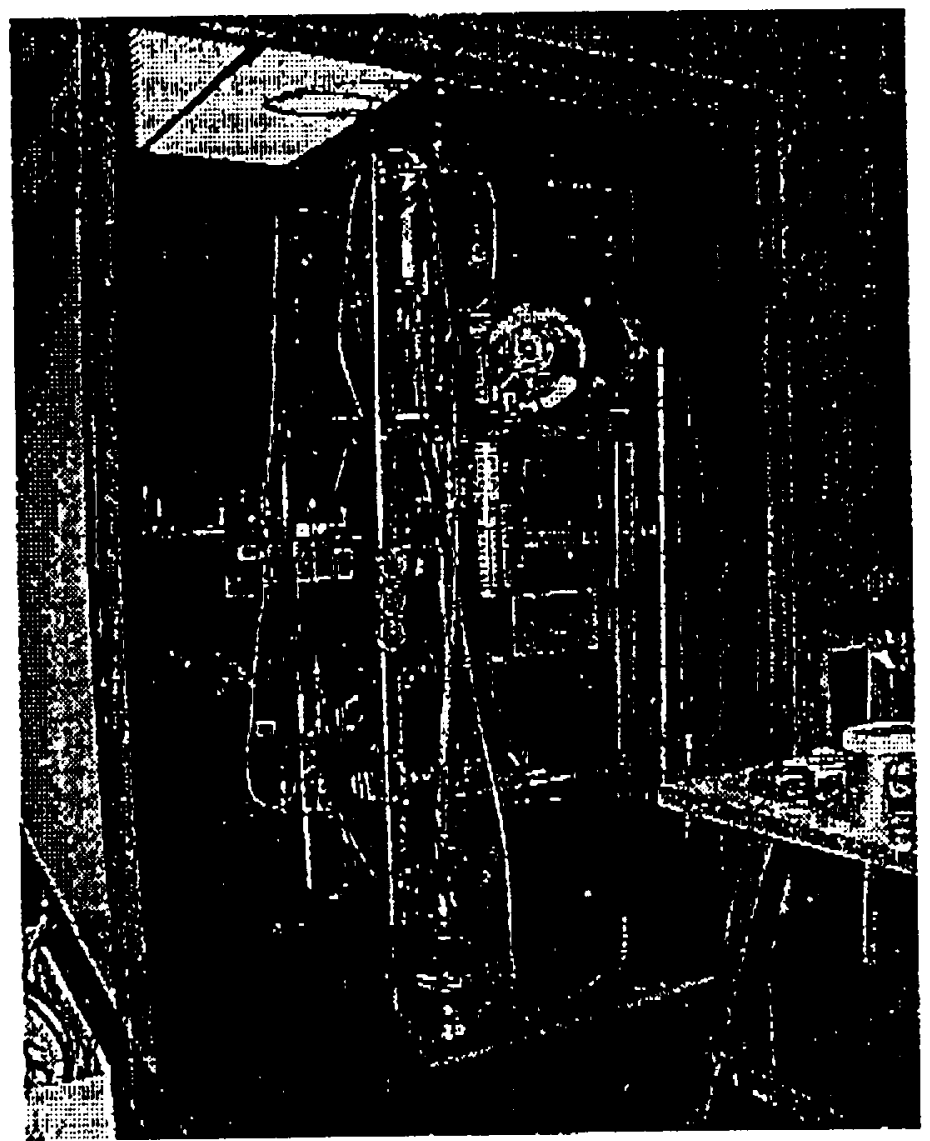

FIGURE 4: DATCO PULSE TUBE CRYOCOOLER FINAL TEST CONFIGURA'TION ASSEMBLED INSIDE TEST RACK WITH ROTARY VALVE, VACUUM TEST CHAMBER, PLENUM TANKS, COOLING FAN, TURBOMOLECULAR AND MECHANICAL VACUUM TANKS 


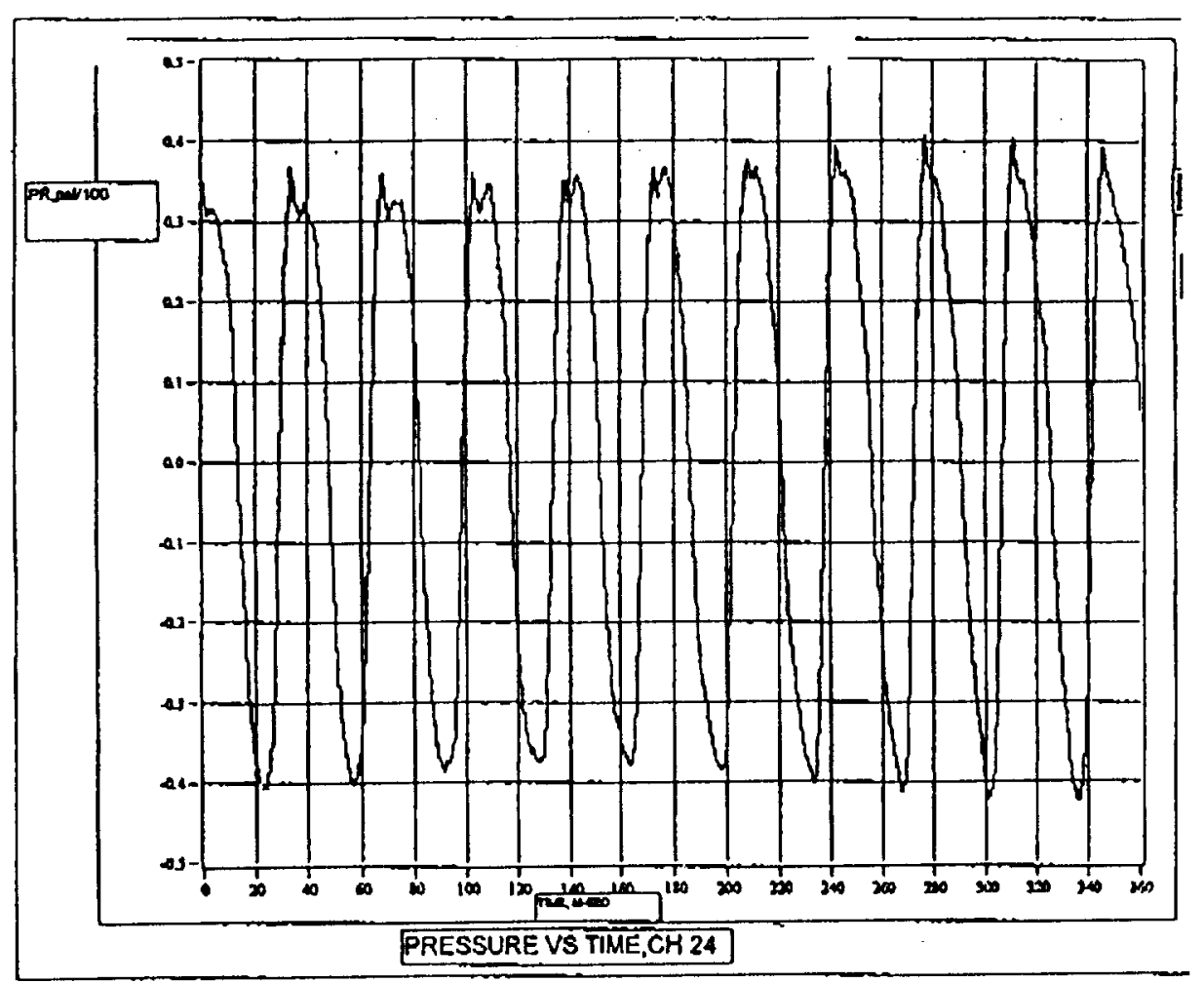

FIGURE 5: PRESSURE PULSES IN HELTUM GAS WORKING FLUD DURING A TYPICAL TEST 


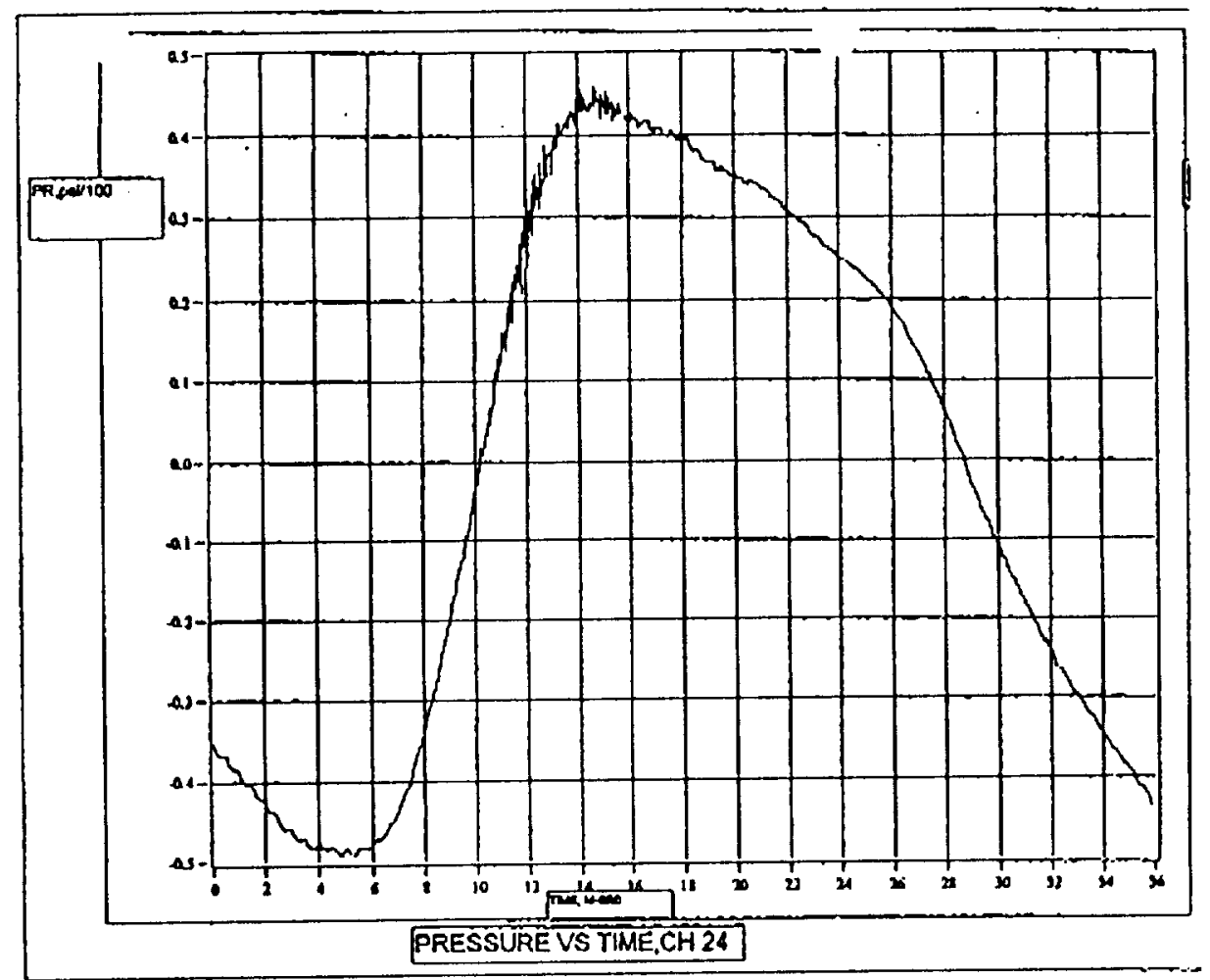

FIGURE 6: HELIUM GAS PRESSURE PULSE WAYEFORM DURING TYPICAL TEST 


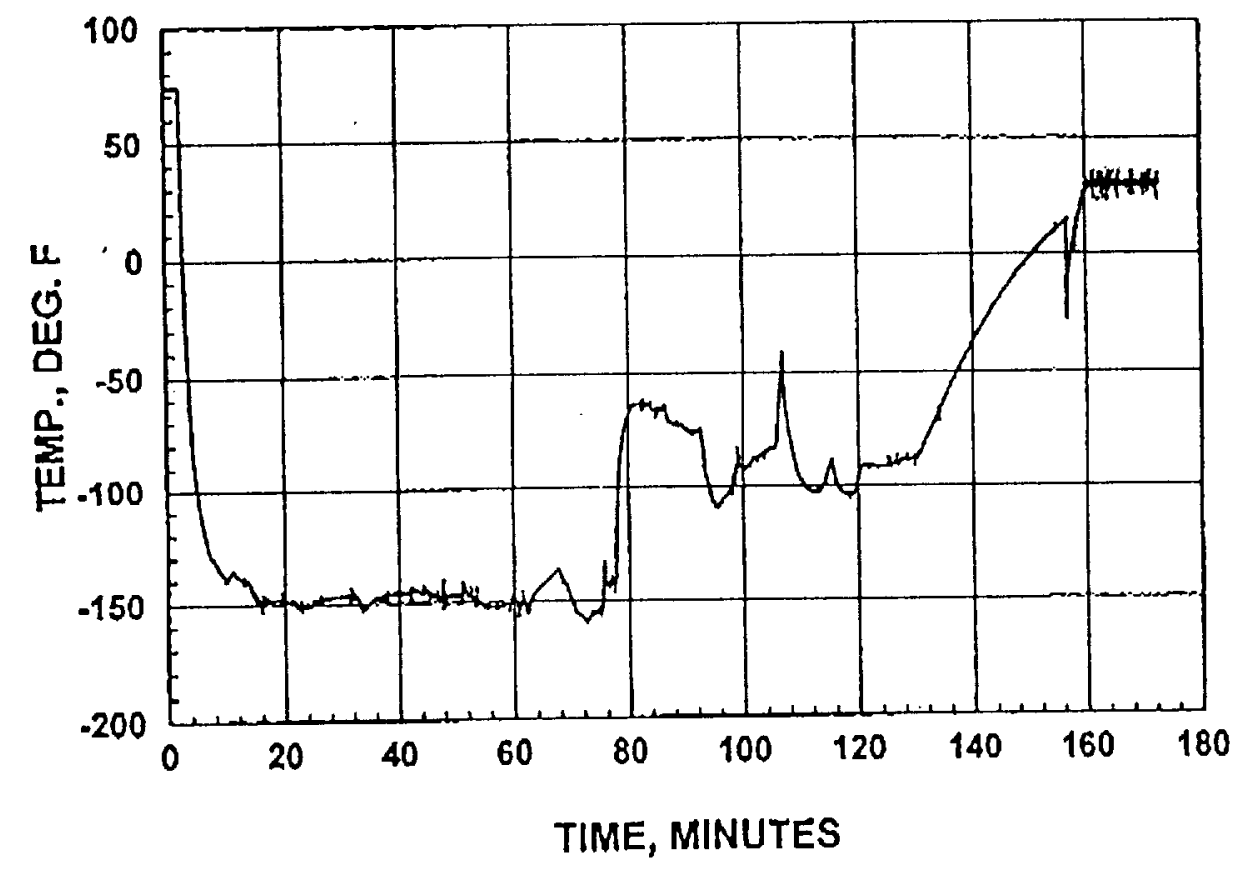

FIGURE 7: TEMPERATURE VERSUS TLME FOR SECOND STAGE COLD END HEAT EXCHANGER BODY DURING TYPICAL TEST 